\title{
El Islam centroamericano
}

\section{The Central American Islam}

\author{
Velvet Rosemberg Fuentes ${ }^{1}$ \\ Columbia University (Estados Unidos)
}

Recibido: 15-01-16

Aprobado: 17-02-16

\section{Resumen}

El Islam latinoamericano es un fenómeno particular que a partir de la última década del siglo pasado ha cobrado especial relevancia entre los estudiosos del tema. Temáticas concretas, abordadas desde el empirismo, han sido problematizadas a partir de consecuencias derivadas de alguno o varios acontecimientos. Ejemplo de ello lo constituyen los atentados contra la sede de la Embajada de Israel en Buenos Aires en marzo de 1992, contra la sede de la Asociación Mutual Israelita Argentina-AMIA- en julio de 1994 y los ataques del 11 de septiembre de 2001 que causaron la destrucción de las Torres Gemelas en Nueva York y daños en la estructura del Pentágono en Estados Unidos. Empero son insuficientes los trabajos que den cuenta del abordaje del Islam en una zona particular, en la que por ejemplo, no haya acontecido algún fenómeno violento. Esta región es Centroamérica.

Palabras-clave: Islam, Centroamérica, presencia musulmana, sociedades de acogida, particularidades.

\footnotetext{
${ }^{1}$ (velvet20@gmail.com) Doctorado en Estudios Latinoamericanos. Investigadora Posdoctoral (Visiting Scholar) en el Departamento de Culturas Latinoamericanas e Ibéricas, Universidad de Columbia, Nueva York, dentro del Programa de Estancias Posdoctorales en el Extranjero para la Consolidación de Grupos de Investigación del Consejo Nacional de Ciencia y Tecnología (Conacyt). Últimas publicaciones: "El estudio del Islam en América Latina: trabajos académicos (1980-2010)", Mañongo, Revista Semestral de Historia y Ciencias Sociales, 44 (2015), pp. 13-41; "La Triple Frontera latinoamericana y el Islam desde las acepciones del concepto de frontera", en Revista Convergencia Crítica, 6 (2015), pp. 113-141; "El Islam centroamericano en números", en Archipiélago. Revista Cultural de Nuestra América, 87 (2015), pp. 56-59.
} 


\begin{abstract}
Islam Latin America is a particular phenomenon from the last decade of the last century has become especially relevant among scholars.Specific topics, addressed from empiricism, they have been problematized from consequences of one or several events. Example of this are the attacks against the headquarters of the Israeli Embassy in Buenos Aires in March 1992 against the headquarters of the Asociación Mutual Israelita Argentina -AMIA - in July 1994 and the attacks of September 11, 2001 that caused the destruction of the Twin Towers in New York and damage the Pentagon structure in America. But jobs are insufficient to realize the approach of Islam in a particular area, in which for example, has not happened a violent phenomenon. This region is Central.
\end{abstract}

Key-words: Islam, Central America, Muslim presence, host societies, peculiarities.

\begin{abstract}
An outsider may look at Islam and wonder how it has survived so many occupations, wars, and periods of foreign rule. The reason is that Islam is more than an empire or a religion. Islam is a culture that does not compartmentalize the varying areas of life, society, or religion... The ultimate goal of Islam is a Muslim world, and the means for achieving such a world are not limited to either spiritual influence or military conquest. Religious conversion, democratic takeover, peaceful submission to Muslim influence, and a forceful jihad are all seen as means to achieve a Muslim world by various Muslims. Muslims "do not envision two civilizations living in harmony, but one, Islam gaining world domination"2.
\end{abstract}

\title{
M. David Sills y Kevin Baggett
}

\section{Introducción}

Las aproximaciones al Islam latinoamericano, además del estudio de asuntos particulares, deben considerar elementos básicos que denoten su caracterización; ya sea por país o por bloques geográficos, este conocimiento es necesario. En este marco, el Islam centroamericano es una materia escasamente examinada. El estado de conocimiento de este tema debe ser robustecido con el propósito de brindar mayores elementos que posibiliten conocer a profundidad la presencia musulmana en esta región.

\footnotetext{
${ }^{2}$ M. David Sills y Kevin Baggett, Islam in Latin America, "Southern Baptist Journal of Theology", 2 (2011), p. 31. 
Mi propósito en este espacio es mostrar los resultados de una pequeña, pero muy significativa investigación alrededor del Islam en Belice, Costa Rica, El Salvador, Guatemala, Honduras, Nicaragua y Panamá. Datos específicos sobre la llegada de los musulmanes, su establecimiento en las sociedades de acogida, cifras de la presencia de esta comunidad, así como particularidades respecto a sus mezquitas entre otros, constituirán los principales elementos que abordaré en este trabajo.

Lo anterior con el fin de demostrar que la presencia musulmana en Centroamérica cobra suma relevancia cada día, y que si bien es cierto que su visibilidad no se asemeja a la que se observa en Argentina o Brasil, donde se han creado los medios y la infraestructura para desarrollar y sostener su sistema de vida, también lo es que los musulmanes centroamericanos han realizado esfuerzos notables con el propósito de generar las condiciones que les permitan desarrollar las actividades propias que implican el profesar el Islam.

\section{Rasgos históricos}

El estudio de la presencia de muslimes en América Latina requiere, sin lugar a dudas, de vastas y extensas investigaciones sustentadas en metodologías robustas que posibiliten, además de argumentar, corroborar los datos esgrimidos. Como bien comenta Hernán G. H. Taboada, "la cuestión todavía necesita mucha investigación, definiciones teóricas y lingüísticas básicas y la colaboración e intercambio entre estudiosos de historia americana e islámica -ambos bandos han emitido suposiciones demasiado generales y se ignoran mutuamente-" 3 . Es por ello que en este breve espacio tan sólo me propongo esbozar algunos rasgos históricos respecto a la llegada y establecimiento de los musulmanes a nuestra América.

Distintos son los caminos que se han trazado al respecto. Más aún estas líneas se han multiplicado cuando los autores reparan en casos específicos. Partiré entonces de lo general y de manera posterior abordaré el caso de América Central.

Estudiosos $^{4}$ de los musulmanes han argumentado que la primera ola de inmigrantes llegó a nuestra América a partir del siglo XVI. Es posible

\footnotetext{
${ }^{3}$ Hernán G. H. Taboada, "El moro en las Indias", en Latinoamérica. Revista de Estudios Latinoamericanos, 39 (2004), p. 115.

${ }^{4}$ Para profundizar en esta línea de investigación véase Hernán G. H. Taboada, "Nuestra América y el islam la mirada en el tercer milenio", en Archipiélago, 40 (2003), pp. 11-14; del mismo autor La sombra del Islam en la conquista de América, México, UNAM-Fondo de Cultura Económica, 2004; Luisa Isabel Álvarez de Toledo, África versus América. La fuerza del paradigma, Córdoba, Junta Islámica, Centro de Documentación y Publicaciones, 2000; y Graciela Azcárate, "La inmigración árabe en América", en Inmigración árabe en América Latina, (2005), disponible en http://rootsweb. com/ domwgw/arabesamerica.htm
} 
explicar entonces al Islam colonial a partir de las tripulaciones cuyo origen era principalmente España y Portugal, en las que viajaban musulmanes que respondían a su condición de esclavos y trabajadores.

Los historiadores argumentan que la segunda ola migratoria procedió de África. En ella, los viajeros respondían a su calidad de esclavos, quienes se insertaron rápidamente en Haití y Brasil ${ }^{5}$ entre otros países. Una clara muestra de ello fue la insurrección ${ }^{6}$ que esclavos musulmanes llevaron a cabo entre el 24 y 25 de enero de 1835, en Bahía. Dicho levantamiento fue conocido como "Revolta dos Malês" o "Levante dos Malês".

Finalmente, los autores también han razonado respecto al arribo de musulmanes a finales del siglo XIX en una tercera ola migratoria. Al respecto, Taboada argumentó que "desde fines del siglo XIX empezó a llegar a Latinoamérica un elemento que en Europa iba a aparecer sólo cincuenta años después, los inmigrantes árabes. En general los que llegaron a América fueron cristianos -o se fingían tales-, pero no dejaron de ser asociados con el Moro: de hecho hay países donde este antiguo nombre fue reciclado, como en Chile"7.

Roberto Marín Guzmán ${ }^{8}$ apuntó que la mayoría de los inmigrantes árabes que no necesariamente musulmanes-, que comenzaron a llegar a Centroamérica a finales del siglo XIX, procedían del Levante mediterráneo -Líbano, Palestina y Siria-.

En términos generales, la última ola migratoria se debió a cambios económicos que tuvieron consecuencias negativas en las familias de artesanos y pequeños comerciantes. La inmigración sirio-libanesa por ejemplo, aunado a lo anterior respondió a transformaciones políticas, religiosas y culturales significativas 9 . Es entonces que la mayor parte de los musulmanes llegó a Latinoamérica entre 1870 y 1930, y se establecieron en Buenos Aires, Sao Paulo, Río de Janeiro y Santiago de Chile entre otras ciudades ${ }^{10}$. Y las principales actividades económicas que desarrollaron fueron el comercio y la industria textil entre otras.

En Belice, de acuerdo a los argumentos expuestos por Abdulmajeed Marin Nuñez ${ }^{11}$, el Islam se introdujo a través de una obra misionera procedente de Medio Oriente, que además de este país arribó a diversas ciudades latinoamericanas pobladas en mayor medida por comunidades afroamericanas

\footnotetext{
${ }^{5}$ M. David Sills y Kevin Baggett, op. cit., p. 31.

${ }^{6}$ Para profundizar en el tema de la presencia musulmana en Brasil véase João José Reis, Rebelião escrava no Brasil. A história do levante dos malês em 1835, São Paulo, Companhia das Letras, 2003.

7 Hernán G. H. Taboada, "Nuestra América y el islam...", op. cit., p. 13.

${ }^{8}$ Roberto Marín Guzmán, Los árabes en Centroamérica [en Abdeluahed Akmir, compilador: Los árabes en América Latina. Historia de una emigración, Madrid, Siglo XXI, 2009], p. 429.

9 Raanan Rein, Introducción [en Raanan Rein, coordinador: Arabes y judios en Iberoamérica. Similitudes, diferencias y tensiones, Madrid, Tres Culturas, 2008], p. 13.

${ }^{10}$ M. David Sills y Kevin Baggett, op. cit., p. 32.

11 Abdulmajeed Marin Nuñez, History of the Muslims in Belize, Indiana, Author House, 2010, p. 227.
} 
que de alguna manera aceptaron las enseñanzas del Islam ortodoxo. Es así que los árabes comenzaron a llegar hace más de cien años. Algunos de los inmigrantes eran musulmanes procedentes de Siria. Pronto se instalaron en la capital y en regiones centrales de los departamentos de Ambergris Caye, Cayo, Corozal y Stann Creek.

La inmigración árabe en Costa Rica se explica especialmente a partir de la tercera ola migratoria descrita con anterioridad. De acuerdo a las reflexiones presentadas por Marín Guzmán, los primeros inmigrantes libaneses comenzaron a arribar a Costa Rica en 1887. Indica que los primeros nombres registrados fueron el de Pablo Sauma Aued y el de Susana Tajan Mekbel. La relación de nombres comenzó a crecer sumándose el de José Tabusj Fallat en 1892, y fue a partir de 1896 que en ésta se registraron 120 nombres más de inmigrantes. En el periodo entre las dos guerras mundiales también se registró el ingreso de 109 inmigrantes libaneses.

No obstante entre 1938 y 1947, el número de libaneses detuvo su rápido crecimiento, toda vez que en este periodo tan sólo se asentó el nombre de diez inmigrantes. Fue hasta finales de la década de los sesenta cuando nuevamente crece la cifra de inmigrantes como consecuencia del comienzo de la Guerra Civil en el Líbano. Empero las cifras no se equipararon a las registradas a principios del siglo $\mathrm{XX}^{12}$.

Sally May ${ }^{13}$ complementó los argumentos esgrimidos por Marín Guzmán al señalar que la comunidad musulmana en este país está conformada por inmigrantes procedentes de Argelia, India, Iraq, Irán, Líbano, Marruecos, Egipto, Somalia, Pakistán, los Territorios Palestinos y Siria. Esta autora explica que en este país un gran número de inmigrantes palestinos arribaron después de la ocupación israelí en Gaza y en la Ribera Occidental en 1967. La mayor parte de los musulmanes que llegaron a Costa Rica en el inicio del presente siglo indica, proceden de zonas urbanas y cuentan con una profesión. Ello, sin lugar a dudas, es un elemento que posibilita su inserción sin mayores dificultades en la sociedad costarricense.

En El Salvador, si bien es cierto no existen datos fundamentados, Pedro Escalante y Abraham Daura ${ }^{14}$ sostienen que la presencia musulmana existe desde la época de la Colonia. Nuevamente es preciso entonces insertar esta llegada y establecimiento en la sociedad salvadoreña en el Islam colonial. Algunos de los elementos físicos que fungen como sostén de esta aseveración se inscriben en la arquitectura aún visible en las ruinas de la antigua iglesia de

\footnotetext{
12 Roberto Marín Guzmán, Los árabes en Centroamérica, op. cit., p. 431.

13 Sally May. El Islam en Costa Rica, México, Centro y Sudamérica. Perfil de un nuevo movimiento religioso, Programa Latinoamericano de Estudios Sociorreligiosos (PROLADES) Online, (2011), p. 3, disponible http://www.prolades.com/profiles/islam_spn.pdf

${ }_{14}$ Pedro Escalante y Abraham Daura Molina, Sobre Moros y Cristianos, y otros Arabismos en El Salvador, San Salvador, Embajada de España en El Salvador y Agencia Española de Cooperación Internacional, 2001, p. 17.
} 
Caluco, Sonsonate y del Pilar, San Vicente. Asimismo destacan que fue en 1619 que un hombre llamado Pedro Soriano fue juzgado por un Tribunal de la Santa Inquisición, toda vez que expresó no defender la fe en Jesucristo por ser la suya perteneciente a los moros ${ }^{15}$.

Los citados autores argumentaron que no existen elementos categóricos que posibiliten confirmar las hipótesis planteadas con anterioridad, y lo mismo ocurre con la ola migratoria que tuvo lugar a partir del siglo XX, a través de la que arribaron a El Salvador inmigrantes procedentes, en su mayoría, de Palestina, ya que no obstante que este fenómeno está robustamente documentado, no se cuentan con datos precisos sobre la especificidad de los musulmanes establecidos en este país. Una de las posibles causas de ello fue la pobreza de la comunicación y organización en todas las actividades destinadas a propagar la práctica de la fe musulmana.

Marín Guzmán ${ }^{16}$ por su parte ha señalado que los palestinos comenzaron a llegar a Centroamérica a partir de la década de 1890, y lo hicieron a través de El Salvador. De acuerdo a la historia oral se recogió como ejemplo la llegada de un palestino a través de puerto de Cutuco y su partida por el puerto de Acajutla. No obstante resulta inverosímil conocer la profesión de su fe religiosa.

Según relata Marín Guzmán ${ }^{17}$, los primeros musulmanes en Guatemala se establecieron a finales del siglo XIX y en mayor medida a principios del XX. Empero no les fue posible mantener una unidad ni una identidad cultural. Ello provocó que permanecieran un corto tiempo en este país y que se desplazaran especialmente hacia América del Sur. Estimo entonces conveniente manifestar que la mayor parte de los musulmanes guatemaltecos son conversos. Esto sucede incluso considerando a aquellos que arribaron durante las décadas de los setenta y ochenta del siglo pasado según informó Jamal Mubarak en 2005, quien funge como presidente de la comunidad islámica de este país. Esta última ola migratoria que llegó a Guatemala se derivó del hecho de que los musulmanes huyeron a la represión militar llevada a cabo por Israel. Aunado a ello, buscaban una mejor calidad de vida.

Respecto a los musulmanes en Honduras, Marín Guzmán ${ }^{18}$ argumenta que los primeros inmigrantes procedentes de Palestina comenzaron a arribar a Centroamérica hacia finales del siglo XIX, por lo que también es posible categorizar su desplazamiento en la tercera ola migratoria de la que hemos hablado. Los inmigrantes llegaron en gran número a Honduras. Ello tuvo una coincidencia con el hecho de que el gobierno hondureño aprobó, en 1906 distintas leyes que regulaban la inmigración, mismas que favorecieron el establecimiento de los viajeros.

\footnotetext{
15 Ídem.

16 Roberto Marín Guzmán, Los árabes en Centroamérica, op. cit., p. 447.

17 Ibídem, p. 477.

18 Ibídem, p. 449.
}

Araucaria. Revista Iberoamericana de Filosofia, Política y Humanidades, año 18, nº 35. Primer semestre de 2016. Pp. 55-83. ISSN 1575-6823 e-ISSN 2340-2199 doi: 10.12795/araucaria.2016.i35.04 
El autor destaca que de 1933 y 1934 se contaba a 592 palestinos debidamente registrados como residentes extranjeros. Este número creció a 812 entre 1936 y 1937. A ello indica, hay que "agregar la inmigración clandestina"19. De estas cifras es imprescindible reconocer que tan sólo, entre el 15 y el $20 \%$ eran musulmanes, es decir, en el periodo de 1933 a 1934 se podían contar entre 88 y 118 musulmanes, y en el lapso de 1936 a 1937, entre 121 y 162 musulmanes.

En lo correspondiente a los musulmanes en Nicaragua, los datos nos aproximan a la inmigración procedente de Ramallah, Jerusalén, Beit Jala y Belén ${ }^{20}$. Es posible, que los migrantes llegaran en mayor número desde finales del siglo XIX hasta 1917, toda vez que fue el momento en el que el Imperio otomano desapareció. No obstante, al igual que en la mayor parte de Centroamérica, no se cuentan con los datos necesarios sobre la especificidad de la llegada y asentamiento de los musulmanes, ya que estos eran confundidos con los otomanos, a los que de manera errónea se les denominaba "turcos". Es por ello que se insertaron en la sociedad nicaragüense sin mayor reparo, toda vez que algunos preferían mantener en secreto la profesión de la fe islámica.

Finalmente, en lo que respecta a Panamá, Raymond Delval ${ }^{21}$ apunta que los primeros musulmanes en arribar a este país fueron los trabajadores indios reclutados en los territorios de Gujarat, Punjab y Bengala, quienes vivieron desde principios del siglo pasado para realizar la excavación del Canal.

\section{EI Islam centroamericano en números}

El objetivo de esta sección es construir un panorama numérico respecto a la presencia musulmana establecida en América Central. El fin último es que el lector cuente con elementos de conocimiento al respecto para aproximarse al Islam en esta región, como lo mencioné con anticipación, tan escasamente abordada hasta el momento.

\footnotetext{
19 Ibídem, pp. 449-450.

${ }^{20}$ Ibídem, p. 463.

21 Raymond Delval, Les musulmans en Amérique Latine et aux Caraïbes, París, L'Harmattan, 1992, pp. 279-280. 


\section{Tabla I. Presencia musulmana en Centroamérica (diversos años)}

\begin{tabular}{|c|c|c|c|c|}
\hline Fuentes & Años & \multicolumn{2}{|c|}{ Cifras } & $\begin{array}{l}\text { Porcentaje u otras } \\
\text { especificaciones }\end{array}$ \\
\hline Mohammed Djinguiz & 1908 & \multicolumn{2}{|c|}{$\begin{array}{l}\text { El total de musulmanes en América } \\
\text { Central y del Sur era igual a } 158,477 \\
\text { (156,121 sunnitas y } 2,356 \text { chiítas). }\end{array}$} & Ninguno \\
\hline \multirow{2}{*}{ Roberto Marín-Guzmán } & 1933-1934 & \multicolumn{2}{|c|}{592 palestinos } & \multirow{2}{*}{$\begin{array}{l}\text { Esta población se ubicaba en Honduras, y } \\
\text { sólo entre el } 15 \% \text { y el } 20 \% \text { eran } \\
\text { musulmanes concentrados en } 17 \text { familias. }\end{array}$} \\
\hline & 1936-1937 & \multicolumn{2}{|c|}{812 palestinos } & \\
\hline \multirow{6}{*}{ Raymond Delval } & & Belice & 200 & \multirow{6}{*}{$\begin{array}{l}\mathrm{El} \text { autor indica que las cifras son } \\
\text { aproximadas }\end{array}$} \\
\hline & & Costa Rica & 500 & \\
\hline & & El Salvador & 300 & \\
\hline & 1992 & Guatemala & 500 & \\
\hline & & Honduras & 200 & \\
\hline & & Nicaragua & 250 & \\
\hline \multirow{2}{*}{ Clifton L. Holland } & Censo de 2000 & \multicolumn{2}{|c|}{243} & \multirow{2}{*}{ Esta cifra sólo corresponde a Belice. } \\
\hline & Censo de 2008 & & & \\
\hline \multirow[t]{2}{*}{ Instituto de Estadística de Belice } & Censo de 2000 & & & \multirow{2}{*}{ Ninguno } \\
\hline & Censo de 2010 & & & \\
\hline \multirow{3}{*}{ Belize Visitor Online } & 2007 & & & \multirow{3}{*}{ Ninguno } \\
\hline & 2010 & & & \\
\hline & 2011 & & & \\
\hline \multirow{7}{*}{$\begin{array}{l}\text { International Religious Freedom } \\
\text { Report }\end{array}$} & \multirow{7}{*}{2012} & Belice & $2 \%$ & $\begin{array}{l}\text { - Población total: } 338,900 \text { habitantes. } \\
\text { - Dentro del porcentaje señalado se } \\
\text { incluyen otros grupos como: La Iglesia } \\
\text { de Jesucristo de los Santos de los } \\
\text { Últimos Días -mormones-, budistas, } \\
\text { hindúes, musulmanes, rastafaris, } \\
\text { Ejército de Salvación y bahá'ís. }\end{array}$ \\
\hline & & Costa Rica & $6 \%$ & $\begin{array}{l}\text { - Población total: } \\
4,600,000 \text { habitantes. } \\
\text { - Dentro del porcentaje señalado se } \\
\text { incluyen otros grupos como: } \\
\text { musulmanes, taoístas, la Conciencia de } \\
\text { Krishna, cienciología, Tenrikyo, y la Fe } \\
\text { Bahai. }\end{array}$ \\
\hline & & El Salvador & $\underset{\text { información }}{\operatorname{Sin}}$ & $\begin{array}{l}\text { - Población total: } \\
6,200,000 \text { habitantes. } \\
\text { - En el estudio se indica que existe un } \\
\text { pequeño número de los testigos de } \\
\text { Jehová, Hare Krishnas, musulmanes, } \\
\text { judíos, budistas y miembros de La } \\
\text { Iglesia de Jesucristo de los Santos de } \\
\text { los Últimos Días } \\
\text { mormones-. }\end{array}$ \\
\hline & & Guatemala & $\begin{array}{c}\text { Sin } \\
\text { información }\end{array}$ & $\begin{array}{l}\text { - Población total: } \\
14,000,000 \text { habitantes. } \\
\text { - En el estudio se indica que existe una } \\
\text { pequeña población musulmana que } \\
\text { reside principalmente en la Ciudad de } \\
\text { Guatemala. }\end{array}$ \\
\hline & & Honduras & 2,000 & $\begin{array}{l}\text { Población total: } \\
8,300,000 \text { habitantes. }\end{array}$ \\
\hline & & Nicaragua & $\begin{array}{l}\text { Menos del } \\
5 \%\end{array}$ & $\begin{array}{l}\text { - Población total: } \\
6,000,000 \text { habitantes. } \\
\text { - En el estudio se indica que los } \\
\text { siguientes grupos constituyen menos } \\
\text { del } 5 \% \text { de la población: Testigos de } \\
\text { Jehová, judíos, La Iglesia de Jesucristo } \\
\text { de los Santos de los Últimos Días } \\
\text {-mormones-, y musulmanes. }\end{array}$ \\
\hline & & Panamá & 12,000 & $\begin{array}{l}\text { - Población total: } \\
3,400,000 \text { habitantes } \\
\text {-de acuerdo al censo de } 2010 \text {-. }\end{array}$ \\
\hline
\end{tabular}


Fuente. Elaboración propia con datos de Bureau of Democracy, Washington, Human Rights and Labor, U. S. Department of State, 2012, disponible en http://www.state.gov/j/drl/rls/irf/religiousfreedom/index.htm?dlid\#wrapper; Mohammed Djinguiz, L'Islam dans l'Amérique centrale et dans l'Amérique du sud, "Revue du monde musulman", VI (1908), pp. 314-318; Clifton L. Holland, Enciclopedia de grupos religiosos en las Américas y la Península Ibérica: religión en Belice, "Programa Latinoamericano de Estudios Sociorreligiosos (PROLADES) Online", (2009), p. 19, disponible en http://www.prolades.com/cra/regions/cam/spanish/rel_guate09spn.pdf; International Religious Freedom Report for 2012, Washington, Departamento de Estado de Estados Unidos, 2012, disponible en http://www.state.gov/j/drl/rls/irf/religiousfreedom/\#wrapper; Roberto Marín-Guzmán, Los inmigrantes palestinos y judios en Centroamérica en los siglos XIX y XX. Aportes económicos y participación política [en Ignacio Klich, compilador: Árabes y judíos en América Latina. Historia, representaciones y desafíos, Buenos Aires, Siglo XXI, 2006], p. 248; National Census Report, Belice, Caricom Capacity Development Programme, 2000, p. 25; Belize Demographics and Population Data. Belize Population Census, Statistical Institute of Belize, Belmopan, 2010, disponible en http://www.belize.com/ belize-demographics; Raymond Delval, op. cit., p. 279, 282-285 y 292; s/n, Belize Religion. Belize Visitor Online, Belice, 2007, disponible en http://www.belizevisitor.com/religion-in-Belize.html; y Muhammad Yusuf Hallar, Los musulmanes en América Latina y sus expectativas para el Nuevo siglo, "Islamérica Online", (1998), disponible en http://www.islamerica.org.ar/dosimpo.html

\section{Tabla II. Presencia musulmana en Centroamérica de acuerdo a The Pew Research Center}

\begin{tabular}{|c|c|c|c|c|c|c|}
\hline País & $\begin{array}{c}\text { Población } \\
\text { musulmana } \\
\text { estimada en } \\
1990\end{array}$ & $\begin{array}{c}\text { Porcentaje de } \\
\text { la población } \\
\text { que era } \\
\text { musulmana } \\
\text { en } 1990\end{array}$ & $\begin{array}{c}\text { Población } \\
\text { musulmana } \\
\text { estimada a } \\
2010\end{array}$ & $\begin{array}{c}\text { Porcentaje de } \\
\text { la población } \\
\text { que era } \\
\text { musulmana } \\
\text { en } 2010\end{array}$ & $\begin{array}{c}\text { Población } \\
\text { musulmana } \\
\text { proyectada a } \\
2030\end{array}$ & $\begin{array}{c}\text { Porcentaje } \\
\text { proyectado a } \\
\text { 2030, de la } \\
\text { población que } \\
\text { será } \\
\text { musulmana }\end{array}$ \\
\hline Belice & $<1,000$ & 0.1 & $<1,000$ & 0.1 & $<1,000$ & 0.1 \\
\hline Costa Rica & $<1,000$ & 0.1 & $<1,000$ & 0.1 & $<1,000$ & 0.1 \\
\hline El Salvador & 1,000 & $<0.1$ & 2,000 & $<0.1$ & 2,000 & $<0.1$ \\
\hline Guatemala & $<1,000$ & $<0.1$ & 1,000 & $<0.1$ & 2,000 & $<0.1$ \\
\hline Honduras & 6,000 & 0.1 & 11,000 & 0.1 & 15,000 & 0.1 \\
\hline Nicaragua & $<1,000$ & $<0.1$ & 1,000 & $<0.1$ & 1,000 & $<0.1$ \\
\hline Panamá & 109,000 & 4.5 & 25,000 & 0.7 & 32,000 & 0.7 \\
\hline
\end{tabular}

Fuente. Extracto de Muslim population by country, "The Future of the Global Muslim Population", Pew Research Center, Religion \& Public Life Project, disponible en http://features.pewforum.org/ muslim-population/

Los datos contenidos en el cuadro 1 denotan, por un lado, generalidades. Mohammed Djinguiz expone una cifra que abarca a América Central y del Sur, es decir sólo excluye a México de América Latina. En realidad esta cifra significa poco. Habría sido sensato estipular los guarismos para cada uno de los bloques geográficos. En este mismo caso se ubican los datos publicados por el International Religious Freedom Report en más del 80\% de la información ostentada. Las cifras manifestadas por Roberto Marín-Guzmán, Raymond Delval y Belize Visitor Online son concretas, no obstante tampoco posibilitan llevar a cabo un análisis comparativo, toda vez que no cuentan con actualización alguna. 
Por otro lado, los datos consignados reflejan disparidades significativas. $\mathrm{Al}$ respecto contamos con información de la presencia musulmana en Honduras expuesta por dos fuentes de información. Marín-Guzmán argumenta que de 1933 a 1937 se contaban 1,404 palestinos, de los que entre $210-15 \%$ - y $280-20 \%$ - eran musulmanes; International Religious Freedom Report indica que en 2012 Honduras contaba con 2,000 habitantes musulmanes. Si consideramos no el 15\%, sino el $20 \%$ de musulmanes, cantidades expuestas por Marín-Guzmán, mismas que significan 280 habitantes y contraponemos este dato con el expuesto por el International Religious Freedom Report ies posible pensar en un crecimiento de 1720 musulmanes en un periodo de 75 años considerando como punto de partida 1937 ?

El cuadro 2 nos muestra un panorama ampliado sobre el comportamiento numérico de la presencia musulmana en Centroamérica, concretamente por las proyecciones que realiza hasta 2030. No obstante los datos parecen estáticos en los casos de Belice, Costa Rica y Nicaragua. Esto puede deberse a que en el estudio se estima un crecimiento natural de la población originaria paralelo al de la presencia musulmana. Los casos de El Salvador, Guatemala, Honduras y Panamá se particularizan porque ponen de manifiesto cambios notables que de manera visual se observan de la siguiente manera.

Gráfica 1. Población musulmana en El Salvador -1990-2030-.

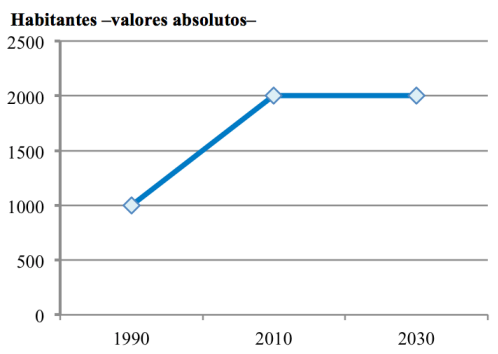

Fuente. Elaboración propia a partir del cuadro 2.

Gráfica 3. Población musulmana en Honduras -1990-2030-

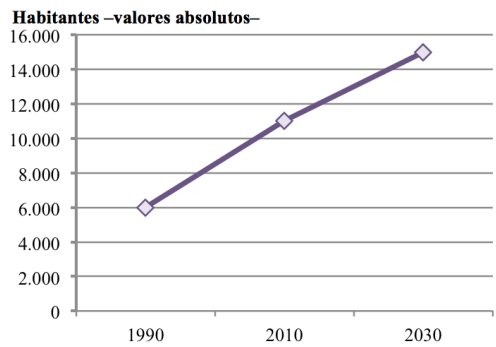

Fuente. Elaboración propia a partir del cuadro 2.
Gráfica 2. Población musulmana en Guatemala -1990-2030-.

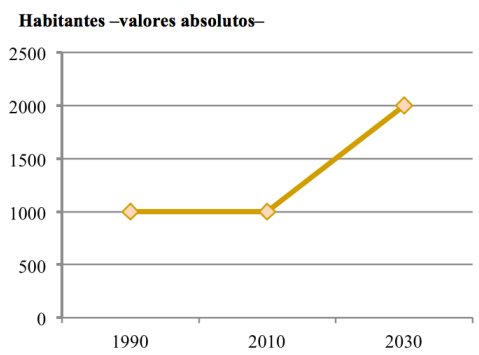

Fuente. Elaboración propia a partir del cuadro 2.

\section{Gráfica 4. Población musulmana en} Panamá -1990-2030-.

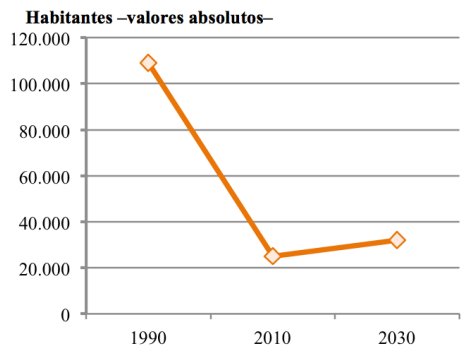

Fuente. Elaboración propia a partir del cuadro 2. 
En la gráfica 1, que muestra el caso de El Salvador, se distingue un crecimiento significativo en la última década del siglo pasado y la primera del presente, con una proyección de un crecimiento prácticamente nulo de 2010 a 2030. Esta situación es inversa en Guatemala -gráfica 2-, es decir el crecimiento significativo se proyectó de 2010 a 2030. En el elemento gráfico 3 , correspondiente a Honduras, es posible observar un incremento constante de la población musulmana, el comportamiento de las cifras no evidencia cambios súbitos, sino sostenidos. Finalmente, en lo que respecta a Panamá -gráfica 4-, las cifras expuestas constituyen un caso muy particular. En el proyecto sobre religión y vida pública auspiciado y llevado a cabo por The Pew Research Center se especifica que se proporcionaron estimaciones para 1990 y 2000 sobre la base de censos nacionales, encuestas demográficas y de salud. De manera precisa, se sugiere que en las fuentes de 1990 se subestimaron sustancialmente el número real de los musulmanes en países como Angola, Chipre, Francia, Gabón, Mozambique y Ucrania. Mientras que se exageró de manera considerable el número de musulmanes establecidos en Colombia, Georgia, Mongolia, Panamá, Taiwán y Vietnam. Asimismo, las estimaciones de 2000 subvaloraron las cifras de los musulmanes en Chipre, Francia, Guatemala, Hungría, Eslovaquia y Vietnam ${ }^{22}$.

Sin lugar a dudas, este sucinto panorama muestra contrastes. Empero, asimismo constituye un esfuerzo para lograr una aproximación a la realidad del Islam a partir de fuentes de información primarias, que dan cuenta de la relevancia de este tema enmarcado en el ámbito geográfico de América Central.

\section{Las mezquitas centroamericanas}

Un espacio que se vuelve propio de quienes practican la fe islámica, un lugar de culto, una mezquita, edificaciones en las que los musulmanes se reúnen cada día, oran, interactúan, comparten.

Privadas, colectivas, grandes y pequeñas, con una arquitectura muy particular en la actualidad, estos espacios son de suma relevancia para la comunidad musulmana establecida en cualquier punto del orbe terrestre. El propósito de este espacio es mostrar el número y la ubicación de las mezquitas con que cuenta Belice, Costa Rica, El Salvador, Guatemala, Honduras, Nicaragua y Panamá. El fin es conocer sobre aquellos recintos que matizan al Islam centroamericano.

Belice cuenta con cinco mezquitas -mapa 1-. Una de ellas se ubica en la capital -Misión Islámica de Belice- que funge también como centro cultural, otra en Belmopán -Islamic Center of Belmopan Masjid ar Rahman-, asimismo

${ }_{22}$ "Muslim population by country", op. cit.

Araucaria. Revista Iberoamericana de Filosofía, Política y Humanidades, año 18, nº 35. Primer semestre de 2016. Pp. 55-83. ISSN 1575-6823 e-ISSN 2340-2199 doi: 10.12795/araucaria.2016.i35.04 
se cuenta con una en Corozal Town -Corozal Mosques-, una más en Dangriga Town -Masjid At Tawheed. The New Medina Society International-y la última en San Pedro -Islamic Masjid-.

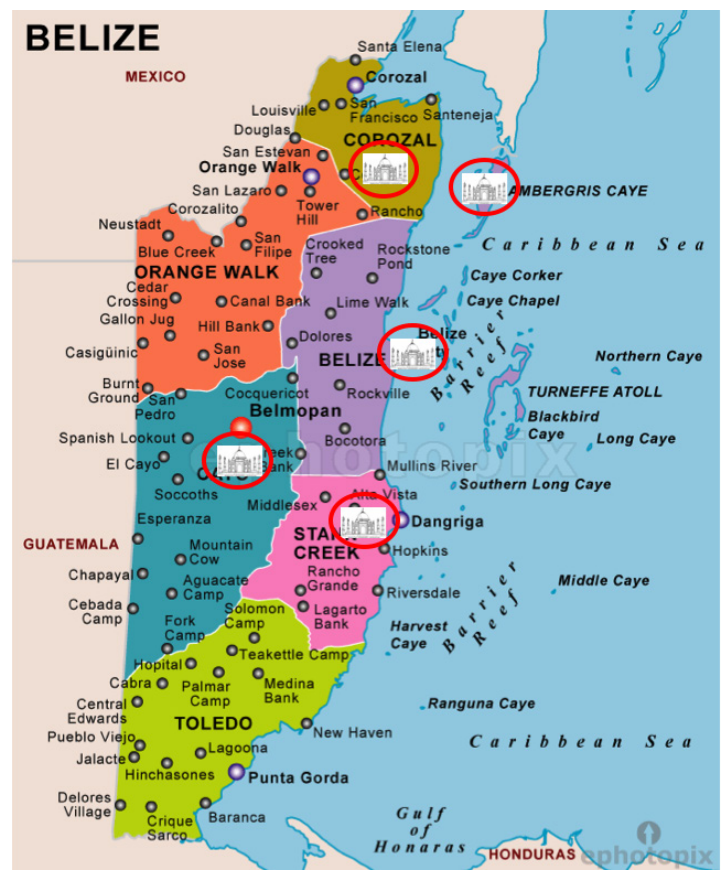

Fuente. Mapa tomado de http://www.diwanalarab.com/spip.php?article33423 con indicaciones propias sobre la localización de las mezquitas.

De igual manera es posible encontrar dos centros culturales. El primero fue conformado por la Misión Islámica de Belice - no hay que perder de vista que esta también es una mezquita- en la ciudad que lleva el mismo nombre. El segundo fue constituido por la Comunidad Islámica y se localiza en Ambergris Cay. En estos espacios se ofrecen diversas actividades entre las que destacan cursos académicos islámicos, de idioma árabe, educación secundaria islámica y formación técnica profesional entre otros.

En lo referente a Costa Rica, este país cuenta con dos mezquitas - mapa 2-. La Mezquita de Omar se ubica en Montelimar -sunita- y la segunda fue construida en San José -chiíta-. De acuerdo a las aportaciones realizadas por Sally $\mathrm{May}^{23}$ al tema, algunos musulmanes se reúnen en una casa de habitación en Sabanilla -región ubicada en la capital del país- con el propósito de orar.

\footnotetext{
${ }^{23}$ Sally May, op. cit., p. 4.
} 
Además, en este país se construyeron dos centros culturales. E1 primero es el llamado Centro Cultural Musulmán, que administra a la Mezquita de Omar. El segundo es el denominado Al Markaz (Dawa-eTabligh), y al igual que el primero se sitúa en la capital, San José.

Por otro lado es dable comentar que en este país también se fundaron diversas organizaciones islámicas. Ejemplo de ello lo constituyen: Muslim Mens Association of Curacao, Musulmanas Costarricenses por la paz y Pura Vida Language Institute. Estos grupos tienen como propósito reunir a hermanos musulmanes, intercambiar experiencias y lecciones de familia, de casa y de educación islámica y, entre otros, ofrecer cursos de lengua árabe.

\section{Mapa 2. Mezquitas en Costa Rica}

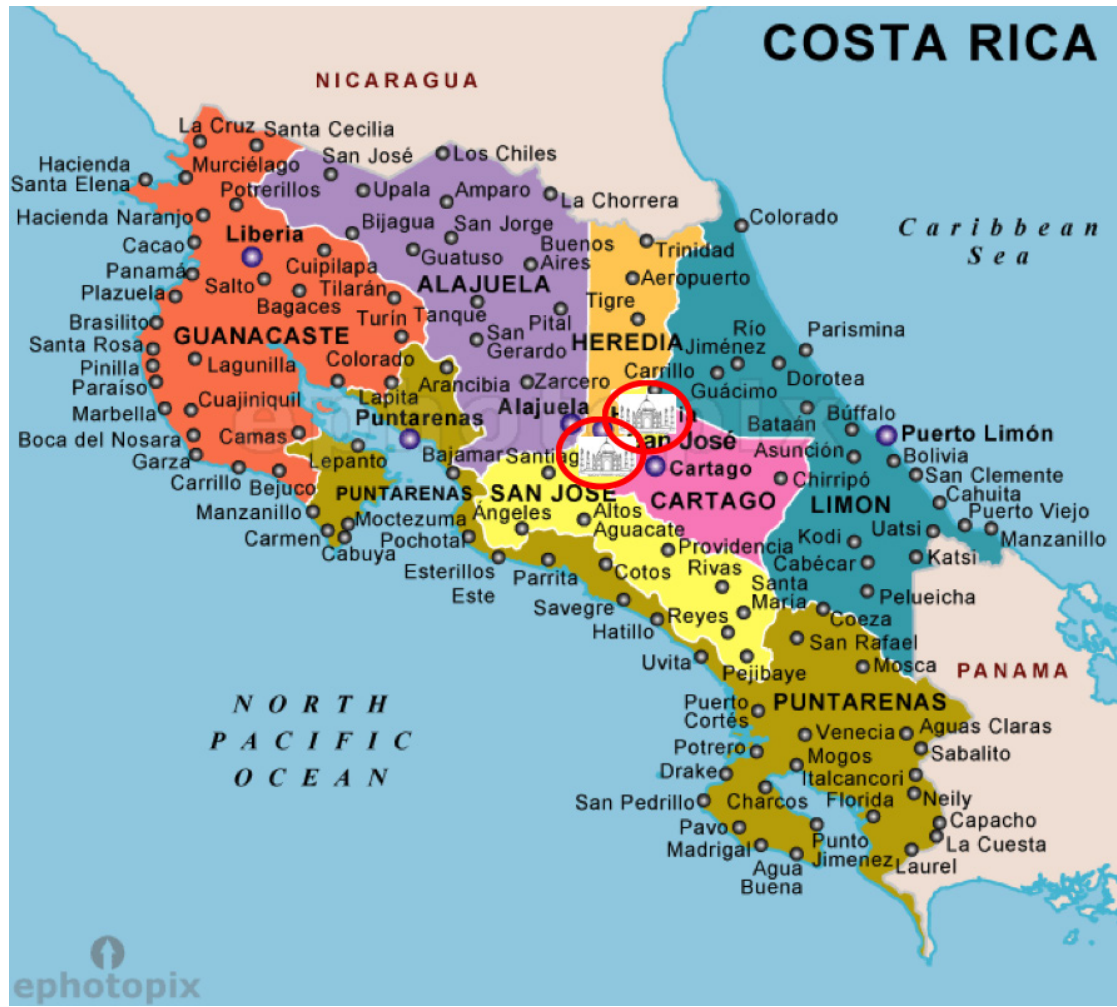

Fuente. Mapa tomado de http://www.diwanalarab.com/spip.php?article33423 con indicaciones propias sobre la localización de las mezquitas. 
El Salvador cuenta con dos mezquitas -mapa 3-. La Mezquita de la Luz fue edificada en la capital, San Salvador, y la Mezquita Anahda se encuentra en Nahuizalco, departamento de Sonsonate.

\section{Mapa 3. Mezquitas en EI Salvador}

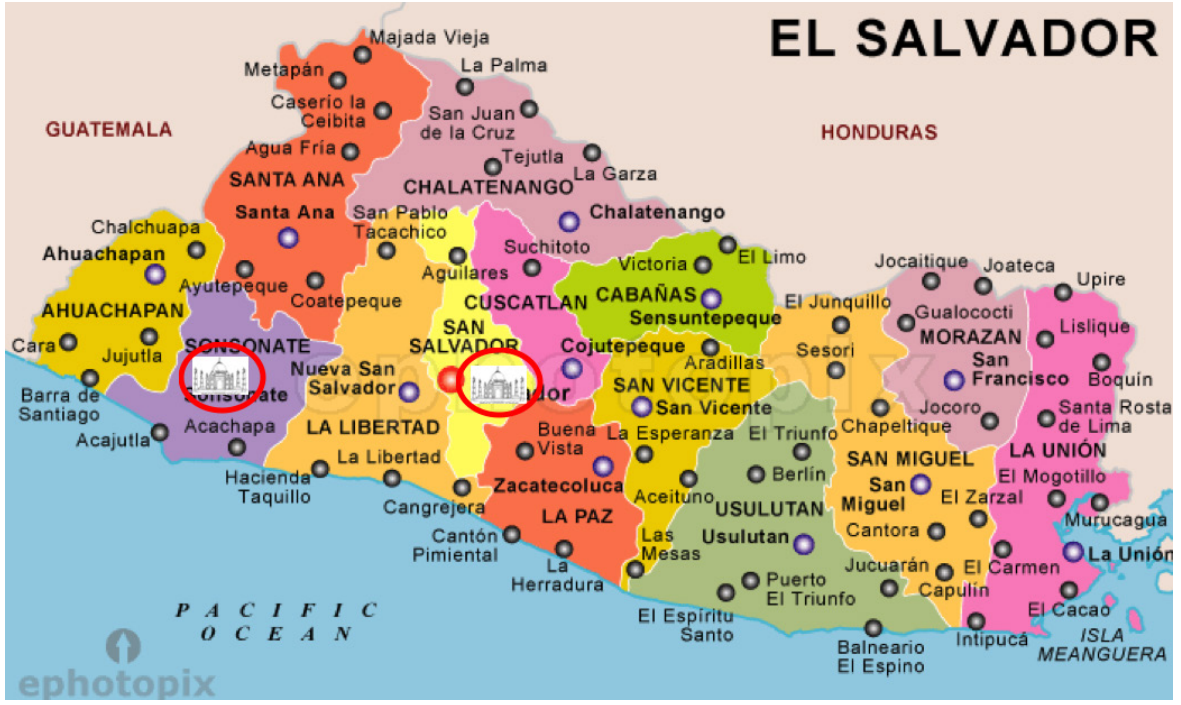

Fuente. Mapa tomado de http://www.diwanalarab.com/spip.php?article33423 con indicaciones propias sobre la localización de las mezquitas.

El Salvador también cuenta con dos centros islámicos. El primero se denomina Centro Islámico Árabe Salvadoreño, que entre otras funciones se encuentra la de administrar a la Mezquita de la Luz. El segundo lleva por nombre Asociación Cultural Islámica Salvadoreña, y al igual que el anterior se sitúa en la capital. Su propósito es difundir el Islam en el ámbito nacional e impartir cursos de literatura islámica entre otros.

Por otro lado, en Guatemala es posible contar con tres mezquitas en la capital -mapa 4-: Mezquita de Aldawaa islámica, Shej Omar Abdullah Sánchez y Masjed Aldawa Aleslamieh. Asimismo, este país cuenta con la denominada Organización de Musulmanas en Guatemala. Este grupo está conformado por mujeres cuyo principal fin es ofrecer asistencia a las mujeres musulmanas y no musulmanas a través de cursos para confeccionar la indumentaria necesaria $-\mathrm{y}$ me atrevo a decir correcta- para llevar a cabo las oraciones, así como alfombras. Esta agrupación de mujeres también imparte cursos sobre la religión islámica, la oración y el ámbito culinario entre otros.

De igual forma la comunidad musulmana estableció el llamado Centro Cultural Islámico de Guatemala, así como la organización denominada 
Musulmanes de Guatemala, que se dedican a realizar visitas a hospitales y a proporcionar alimentos a las personas de escasos recursos. Finalmente es posible contar con el Centro Islámico para Asuntos de la Mujer, cuyas principales tareas están enfocadas a impartir clases sobre el Islam, idioma árabe y español para extranjeros, así como bordado de cuadros. De igual manera proporcionan libros y venden trajes para realizar las oraciones. Todos estos centros culturales se ubican en la capital.

\section{Mapa 4. Mezquitas en Guatemala}

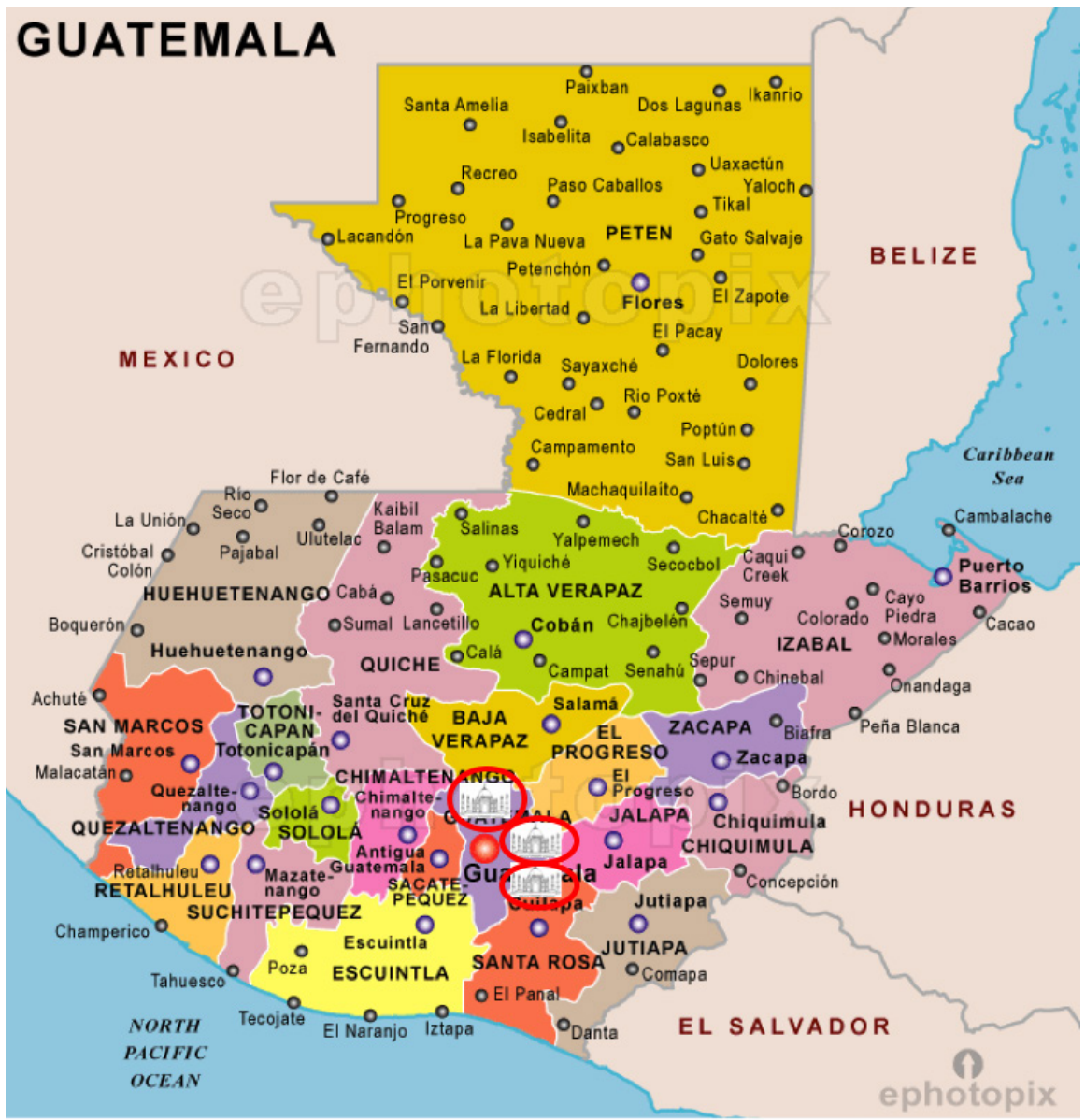

Fuente. Mapa tomado de http://www.diwanalarab.com/spip.php?article33423 con indicaciones propias sobre la localización de las mezquitas. 
Respecto a Honduras se encuentran establecidas dos mezquitas - mapa 5-. La Mezquita de Tegucigalpa fue construida en la capital del país y el Islamic Center of Honduras se sitúa en San Pedro Sula. Asimismo se edificaron dos centros islámicos. El primero se denomina Foundation Islamic Society of Honduras, que administra la Mezquita de Tegucigalpa. Aunado a ello lleva a cabo campañas de difusión del Islam y realiza obras de caridad entre las personas de escasos recursos.

El segundo centro cultural lleva por nombre Fundación Islámica de Honduras y se encuentra establecido en San Pedro Sula.

\section{Mapa 5. Mezquitas en Honduras}

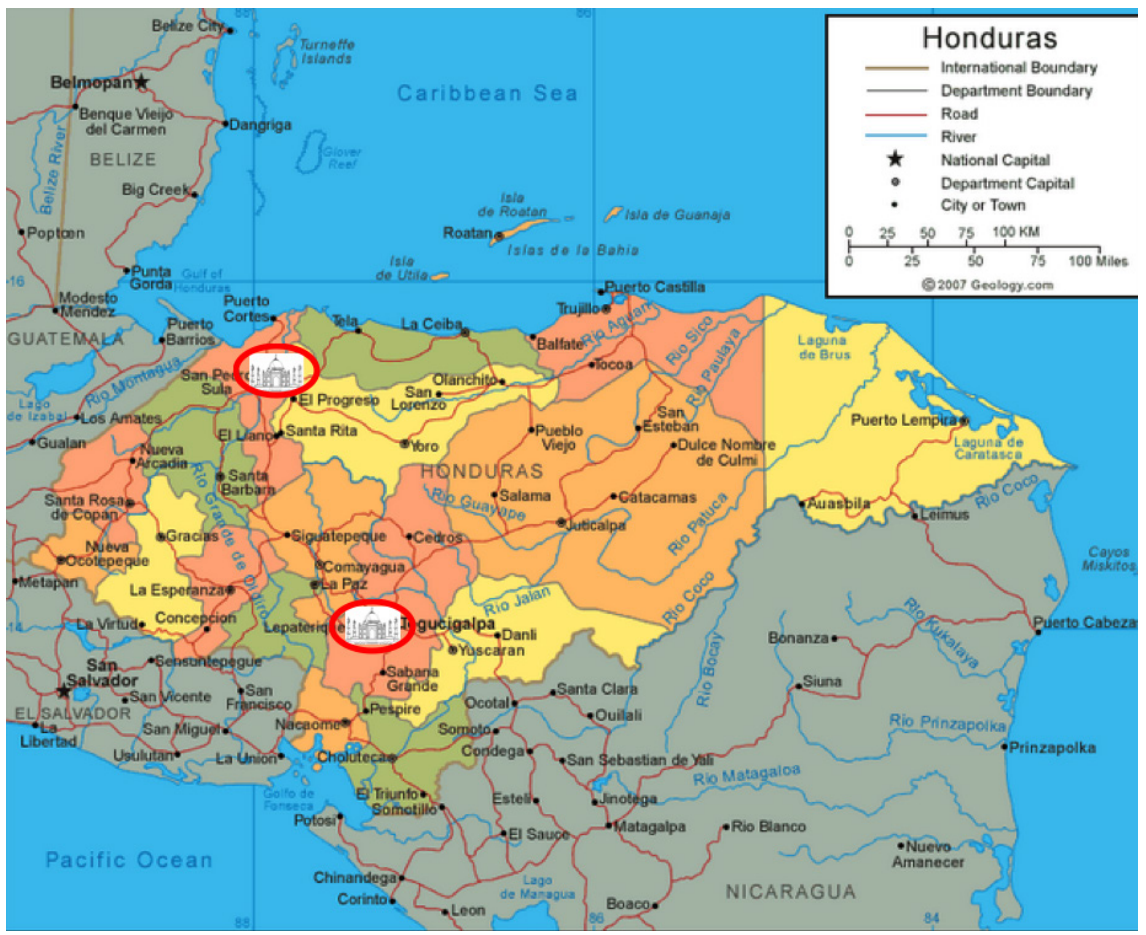

Fuente. Mapa tomado de http://www.diwanalarab.com/spip.php?article33423 con indicaciones propias sobre la localización de las mezquitas.

En Nicaragua se ubican dos mezquitas -mapa 6-. La Asociación Cultural Nicaragüense Islámica está construida en la capital, los Musulmanes Sunníes de Granada se sitúan en la región del mismo nombre. Ambas edificaciones también fungen como centros culturales islámicos, cuya finalidad es servir como centro de reunión y brindar información a los musulmanes que vacacionan en el país. 


\section{Mapa 6. Mezquitas en Nicaragua}

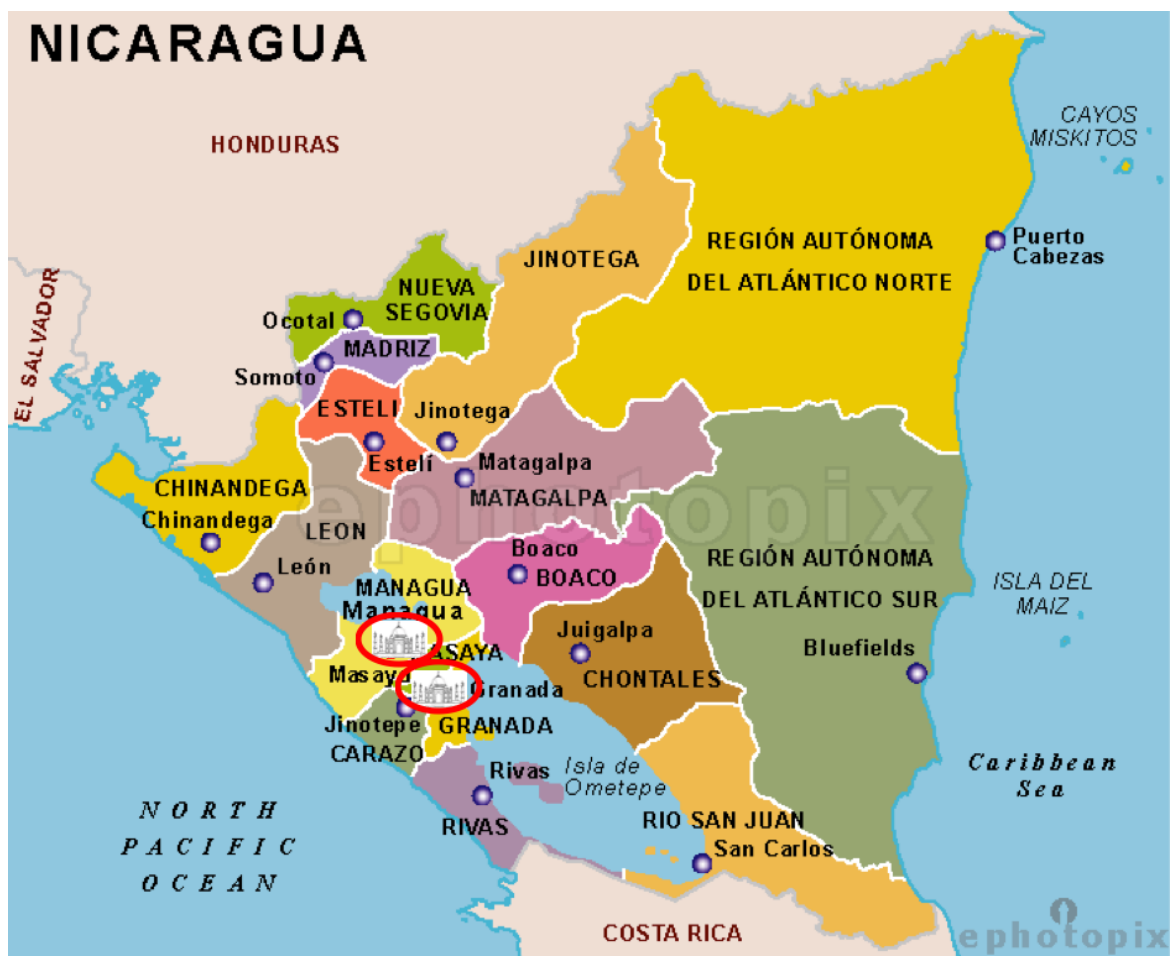

Fuente. Mapa tomado de http://www.diwanalarab.com/spip.php?article33423 con indicaciones propias sobre la localización de las mezquitas.

Finalmente, en Panamá es posible contar tres mezquitas. La Fundación Islámica de Panamá -Mezquita Yamáa- y la Mezquita Madina Msjid fueron construidas en la capital del país, la Asociación Islámica de Changuinola Mezquita Al Nur-se edificó en Bocas del Toro.

De igual manera, Panamá cuenta con los siguientes centros culturales islámicos: la denominada Academia Bilingüe árabe-Panameña establecido en Colón, la Asociación Islámica Chiriquí dispuesta en la región del mismo nombre, el Centro Cultural Islámico situado en Colón, el Centro de Estudios e Investigaciones Islámicas edificado en El Dorado, el Islamic Center Santiago situado en Santiago, Veraguas, y el Centro Islámico de Azuero construido en Chitre, Azuero. Estos centros culturales compartes las mismas tareas que los citados con anterioridad. 


\section{Mapa 7. Mezquitas en Panamá}

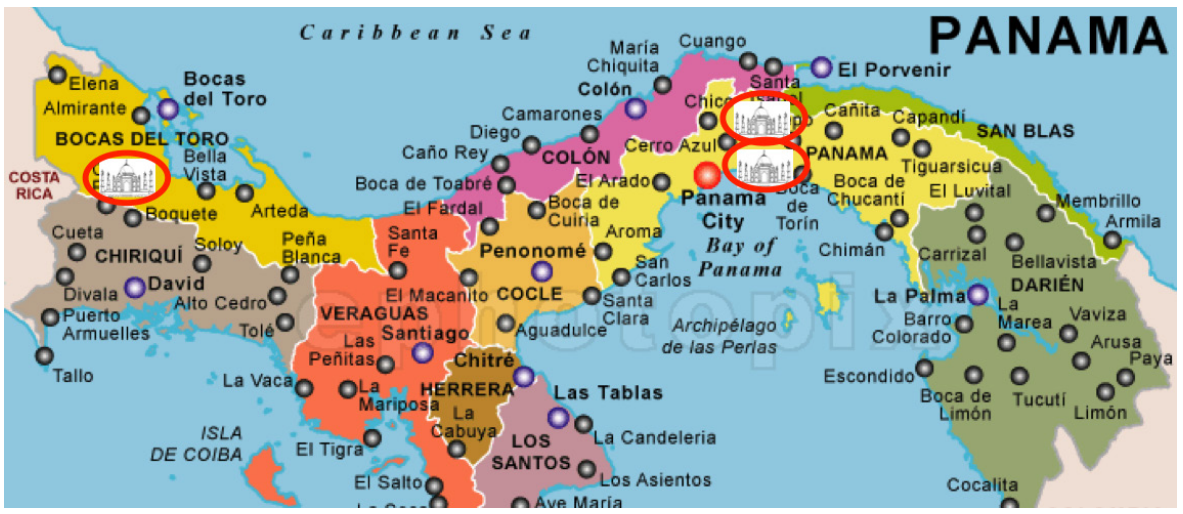

Fuente. Mapa tomado de http://www.diwanalarab.com/spip.php?article33423 con indicaciones propias sobre la localización de las mezquitas

\section{Dificultades en el estudio del Islam centroamericano}

Al abordar el tema del Islam centroamericano, las tareas implícitas en el extraordinario camino de la investigación, así como en el de la exposición de los resultados se complican. El fenómeno del Islam latinoamericano es reciente. Datos concretos -aunque no siempre fiables- tuvieron su origen a mediados de la década del siglo pasado, los más confiables aparecieron a principios de la década de los ochenta, también del siglo XX.

Gran parte de las aportaciones de los especialistas y no especialistas en el tema se centraron en América Latina y el Caribe. Algunos países centroamericanos fueron abordados de manera general; sus particularidades fueron dejadas de lado. Ello se debe, en gran medida, a la escasez de información gubernamental. La investigación empírica es la única que ha dado frutos, aunque también parciales y dispersos.

Respecto a la información gubernamental veamos cada caso. El gobierno de Belice cuenta con 16 Ministerios, y es el Ministerio General de la República el que tiene la facultad para registrar los centros religiosos que se establecen en el país, así como cobrar los derechos que fija la ley. Estas labores las realiza a través de Belize Companies \& Corporate Affairs Registry. Sin embargo, la información no está disponible al público.

Por su parte, el Instituto de Estadística, que se estableció el 1 de abril de 2007 en sustitución de la Oficina Central de Estadística, llevó a cabo censos en 2000 y 2010 , en cuyos resultados figuraron algunas cifras inconexas respecto a las prácticas religiosas de la población. 
Más allá de las instituciones citadas, Belice no cuenta con institución alguna que vele por el respeto a la libertad de culto, por la libertad de cambiar de religión o de creencias, así como por la libertad de manifestar y propagar la religión o creencias de los ciudadanos. Fuera de toda duda, la existencia de una institución que velara por el cumplimiento de estos derechos, que están previstos en la Constitución ${ }^{24}$, brindaría datos estadísticos fundamentales para el estudio de prácticamente cualquier credo religioso.

En lo referente a Costa Rica, este país cuenta con 15 Ministerios. El gobierno le otorgó facultades al Ministerio de Relaciones Exteriores y Culto para brindar servicio, entre otras, a las asociaciones religiosas registradas. Esto se observa en su misión que cito a continuación:

El Ministerio de Relaciones Exteriores y Culto es el ente rector de las relaciones exteriores del país, al cual le corresponde representar al Estado y defender sus intereses políticos, económicos y sociales, así como los de sus nacionales en el exterior, mediante el ejercicio del derecho diplomático y consular, y las actividades de promoción, ejecutadas por un servicio exterior profesionalizado, apoyado por un servicio interno con capacidad técnica y profesional y un servicio administrativo experto, que brinde servicios de eficiencia, excelencia y calidad, a los usuarios internos y externos, al ciudadano nacional, al cuerpo diplomático acreditado en Costa Rica, y a la Iglesia Católica y otras denominaciones religiosas oficialmente registradas ${ }^{25}$.

Como se lee, el ámbito exterior está vinculado con el religioso. Una de las explicaciones de esta concatenación se encuentra en el reconocimiento que el gobierno realiza a todas las creencias religiosas que se encuentran fuera del ámbito católico -ya que se reconoce a esta como la primordial- y que obviamente han llegado al país, a lo largo del tiempo, desde otras latitudes del orbe. Es decir, las otras religiones son consideradas como un agente externo que de alguna manera ha llegado a modificar las creencias de los habitantes convirtiéndolos a ellas. Este fenómeno es respetado por el gobierno. Sin embargo, ello no es suficiente para que sean consideradas de gran relevancia para el país como lo es la Iglesia Católica. Para cumplir su misión, el gobierno costarricense creó la Dirección Adjunta de Culto, cuyo objetivo principal es:

\footnotetext{
${ }^{24}$ Para profundizar en el tema véase Constitución de Belice, Parte II Protección de los derechos fundamentales y libertades, Belice, 1981, disponible en http://pdba.georgetown.edu/Constitutions/ Belize/belize81.html\#mozTocId483751

${ }^{25}$ Misión, visión y objetivos institucionales, Ministerio de Relaciones Exteriores y Culto, San José, Gobierno de la República de Costa Rica, 2014, disponible en http://www.rree.go.cr/?sec=ministerio $\&$ cat $=$ acerca \& cont $=401$
} 
...velar por las buenas relaciones entre el Estado y la Iglesia Católica, Apostólica y Romana, así como por el cumplimiento del artículo 75 de la Constitución Política, en lo referente a la no discriminación religiosa, Igualmente atender a la Conferencia Episcopal de Costa Rica y a la Nunciatura Apostólica para lo pertinente. Asimismo completará la información de todas aquellas organizaciones religiosas debidamente inscritas por el Estado, teniendo en cuenta los criterios de historicidad, estructura eclesiástica y universalidad ${ }^{26}$.

Es interesante notar que dentro de las principales funciones de esta Dirección se encuentra el participar en los actos de investidura religiosa de obispos, pastores y ministros religiosos, dar seguimiento a las publicaciones en la prensa sobre las diferentes organizaciones religiosas, monitoreando los temas de religión, credos y relaciones entre las iglesias, monitorear los proyectos de ley que sean presentados en las Comisiones respectivas de la Asamblea Legislativa y que tengan relación con la materia a su cargo, conformar el listado de organizaciones religiosas debidamente inscritas y legalizadas, y colaborar y asesorar a las Temporalidades de la Iglesia Católica, Apostólica, Romana, sobre los trámites y documentos para efectos de la disponibilidad de recursos del Estado - esto en coordinación con el Departamento Financiero-.

La ausencia de la laicidad en la relación entre el gobierno costarricense y la religión debería tener como consecuencia la divulgación de la situación religiosa del país. Empero esta no existe. Los listados de las asociaciones religiosas registradas no están disponibles al público, tampoco se hace mención alguna sobre su situación en las memorias institucionales del Ministerio de Relaciones Exteriores y Culto, y las leyes registrales del Registro Nacional no develan las normas que debieran reglamentar el registro de las asociaciones religiosas incluyendo a la Iglesia Católica. Todo ello constituye una prueba de la ausencia de información gubernamental en torno al tema que nos ocupa.

¿Qué ocurre en el caso de El Salvador? Este país cuenta con 11 Ministerios, y es el del Interior ${ }^{27}$ el encargado de registrar, regular y supervisar las finanzas de las organizaciones no gubernamentales-ONG's-, iglesias no católicas y otros grupos religiosos. Y de manera específica, es

\footnotetext{
${ }^{26}$ Dirección Adjunta de Culto, San José, Gobierno de la República de Costa Rica, 2014, disponible en $h t t p: / / w w w . r r e e . g o . c r /$ index.php? $\mathrm{sec}=$ ministerio\& cat $=$ protocolo\& cont $=447$

${ }^{27}$ Con el fin de evitar confusiones en el lector es preciso aclarar que el Ministerio del Interior también es denominado como Ministerio de Gobernación. Como ejemplo véase la Ley de Asociaciones y Fundaciones sin fines de lucro, núm. 894, tomo 333, Diario Oficial, San Salvador, Ministerio del Interior, 17 de diciembre de 1996.
} 
a través de la Dirección General de Asociaciones y Fundaciones sin Fines de Lucro -DGFASFL-, que se ocupa de registrar a otros grupos religiosos distintos a la Iglesia Católica, toda vez que la normatividad ${ }^{28}$ mandata que esta acción la deben realizar dichas agrupaciones con el fin de obtener personería jurídica, y con ello ser sujetos a exención de impuestos.

Es dable manifestar que no obstante que las asociaciones religiosas lleven a cabo su trámite ${ }^{29}$ de registro, no son aprobadas por el gobierno en todos los casos. Empero tampoco existe información oficial respecto al número de peticiones de nuevo registro, aprobadas, pendientes y denegadas. Lo mismo ocurre con el número de agrupaciones registradas. Es decir, el Ministerio del Interior no ha publicado, para su consulta, los registros pertinentes. Ello suma interrogantes respecto a las cifras oficiales de musulmanes establecidos en este país. Finalmente, esta situación también se extiende a la Iglesia Católica. Ello no obstante que es considerada como el principal credo, tal como ocurre en el caso de Costa Rica, que se analizó con anterioridad.

En lo que concierne a Guatemala, el gobierno realiza dos distinciones respecto al registro de las agrupaciones religiosas que es preciso aludir. Primera, de manera oficial no requiere el registro de ninguna entidad religiosa con el fin de reconocerla como tal. Es decir, no se necesita que se inscriban a un registro para que los adeptos practiquen su dogma. Segunda, sin embargo, si es necesario que se registren como entidades legales con el fin de que puedan realizar negocios, celebrar contratos y ser sujetos de exención de impuestos. Estas tareas las lleva a cabo el Ministerio de Gobernación, que forma parte de los 14 Ministerios encargados de ejecutar la política interna y externa del país.

La Iglesia Católica en Guatemala se encuentra en una situación similar que la que se observa en Costa Rica y El Salvador, toda vez que su personalidad jurídica es reconocida sin ningún inconveniente, por lo que no debe inscribirse en el Registro. Cualquier otra agrupación religiosa debe conformarse de por al menos 25 miembros para que su registro proceda. Si bien es cierto que este requisito pudiese ser considerado irrelevante, también lo es que su condición de simplicidad

${ }^{28}$ Son diversas las leyes que están estrechamente relacionadas con el registro de las organizaciones y fundaciones sin fines de lucro. Al respecto véase Ley de Asociaciones y Fundaciones sin fines de lucro, op. cit.; Reglamento de la Ley de Asociaciones y Fundaciones sin fines de lucro, núm. 78, tomo 336, Diario Oficial, San Salvador, Ministerio del Interior, 21 de agosto de 1997.

${ }^{29}$ Respecto a los casos hasta ahora analizados es relevante exponer que en El Salvador es posible acceder al documento Modelo o Instructivo de Asociación para solicitar la aprobación de estatutos y reconocimiento de la personalidad jurídica. La publicación de este documento oficial simplifica, sin lugar a dudas, las gestiones que deben llevar a cabo las agrupaciones religiosas con el propósito de obtener su registro.

Araucaria. Revista Iberoamericana de Filosofía, Política y Humanidades, año 18, $\mathrm{n}^{\circ}$ 35. Primer semestre de 2016. Pp. 55-83. ISSN 1575-6823 e-ISSN 2340-2199 doi: 10.12795/araucaria.2016.i35.04 
cambiaría, toda vez que aportaría datos concretos que posibilitarían conocer el número básico, mínimo de musulmanes oficialmente registrados si es que los imanes procedieran a registrar las mezquitas. No obstante esta tarea tiene limitaciones, toda vez que aunque procedan los registros de las mezquitas, el Ministerio de Gobernación no ha puesto a disposición del público la información pertinente para su consulta.

Está claro también que la desventaja de la imposición de este requerimiento radica en que probablemente existen lugares acondicionados para llevar a cabo las oraciones y en los que no necesariamente se reúnen más de 25 musulmanes, por lo que tampoco se vuelve fundamental su registro. Es así que estos guarismos y otra información relacionada con la presencia musulmana se pierde como consecuencia de un mar administrativo prácticamente inaccesible.

Honduras no presenta mayores diferencias respecto al registro de las religiones que los casos anteriormente analizados. Empero existen algunas particularidades en las que es preciso detenernos un poco a reflexionar. En este país la Iglesia Católica está reconocida bajo la ley como "religión". Es preponderante tanto, que existe un vínculo bastante estrecho entre ésta y las fuerzas armadas. De igual manera, la Iglesia Protestante y diversas comisiones gubernamentales dependientes de la Secretaría de Gobernación y Justicia también han mantenido una robusta correlación. Sin embargo, a esta última y a cualquier otra agrupación, el gobierno las cataloga sólo como "asociaciones religiosas", y es bajo esta denominación que son susceptibles de ser sujetos de exenciones de impuestos, ya que se les reconoce su personalidad jurídica.

La Secretaría de Gobernación y Justicia es el ente encargado de llevar a cabo las tareas relacionadas con el registro de las asociaciones, entre ellas turnar las solicitudes a la Procuraduría General de la República, que se ocupa de elaborar un dictamen a través del que se certifica que las organizaciones religiosas solicitantes cumplen o no con los requisitos necesarios para obtener su registro como "asociaciones religiosas". Es claro que el Islam se inscribe en este grupo. Sin embargo, no se cuenta con información respecto al número de trámites llevados a cabo, cuántos de ellos han sido aprobados y cuánto no lo han sido.

El reconocimiento gubernamental a la Iglesia Católica como una religión, si bien no oficial con mención en las Constituciones, pero sí preponderante, se ha convertido en un patrón en los países centroamericanos. En Nicaragua, al igual que en los casos anteriores, la presencia histórica de esta iglesia ha posibilitado generar un vínculo próximo con el gobierno, tanto que podríamos hablar de un catolicismo 
político, toda vez que el accionar de esta agrupación religiosa tiene incidencia directa en el ámbito de la política nicaragüense.

Las asociaciones religiosas pueden obtener su registro con el fin de que se les reconozca su personalidad jurídica y, al igual que los casos anteriores, sean sujetos de exención de impuestos. La Junta de Gobierno de Reconstrucción Nacional de la República de Nicaragua aprobó, el 15 de noviembre de 1983, el Decreto número 1346, que refiere a la Ley sobre Asociaciones y Registro Central de Personas Jurídicas, normatividad cuyo objetivo es...

...regular la constitución, autorización, funcionamiento y extinción de las asociaciones civiles y religiosas que sin fines de lucro existen en el país y de las que en el futuro se organicen de conformidad con el ejercicio del derecho de asociación consagrado en el Estatuto de Derechos y Garantías de los Nicaragüenses... ${ }^{30}$.

El Ministerio de Gobernación es el ente encargado, a través del Departamento de Registro y Control de Asociaciones, de recibir y atender en el proceso las solicitudes de nuevos registros. Sin embargo, es la Asamblea Nacional el órgano encargado de aprobar o negar el registro.

En Nicaragua también se reproduce lo que pareciera ser un modelo en los países centroamericanos, toda vez que no es posible contar con acceso a los registros de las agrupaciones religiosas cuya personalidad jurídica fue reconocida por la ley. Por su parte, el Instituto Nacional de Estadísticas y Censos expuso algunas cifras de los censos realizados en 1995 y en 2005 respectivamente. Empero los datos se actualizan cada dos lustros, razón por la que es dable afirmar que la información oficial sobre la presencia musulmana en el país es insuficiente y endeble.

Finalmente ¿qué ocurre en Panamá? Los grupos religiosos tienen la posibilidad de obtener su reconocimiento como "asociaciones religiosas" y con ello, al igual que en los casos anteriores, obtener el reconocimiento de su personalidad jurídica. El Ministerio de Gobierno es el ente encargado de realizar las tareas relacionadas con el registro. Al igual que en Belice, Costa Rica, El Salvador, Guatemala y Honduras, los registros de las asociaciones religiosas son inasequibles al público. Por ello tampoco es viable contar con información oficial respecto al número de mezquitas y musulmanes establecidos en este país.

${ }^{30}$ Ley sobre Asociaciones y Registro Central de Personas Jurídicas, Decreto núm. 1346, Managua, Junta de Gobierno de Reconstrucción Nacional de la República de Nicaragua, 15 de Noviembre de 1983 , p. 2.

Araucaria. Revista Iberoamericana de Filosofía, Política y Humanidades, año 18, n 35 . Primer semestre de 2016. Pp. 55-83. ISSN 1575-6823 e-ISSN 2340-2199 doi: 10.12795/araucaria.2016.i35.04 
Ahora ¿qué ocurre con la investigación empírica? Mi propósito no es realizar en este espacio una revisión del estado del arte respecto a las publicaciones sobre el Islam centroamericano. Empero sí sostener que las obras académicas respecto al tema han proliferado de manera especial en el presente siglo, aunque aún es preciso contender, por un lado, con su dispersión y, por otro, con argumentos endebles que sólo se sostienen en andamiajes creados por percepciones.

De manera general, las aportaciones ${ }^{31}$ que muestran datos concisos y fundamentados se han centrado en el ámbito histórico, específicamente en el fenómeno que las migraciones representan más que en el establecimiento y movilidad de los migrantes musulmanes.

\section{Conclusiones}

A modo de valoración global es imprescindible señalar que los musulmanes ubicados en Centroamérica han llevado a cabo notables esfuerzos con el propósito de adaptarse a una región diversa a Medio Oriente. Tanto aquellos que son musulmanes de origen como quienes han nacido de padres musulmanes, han procurado llevar a buen puerto todas las acciones enmarcadas en el Islam como un sistema de vida. Un claro ejemplo de ello lo constituye su empeño en la construcción de mezquitas en las que puedan celebrar los rituales que implican las oraciones cotidianas, así como los centros educativos a través de los que se transfieren conocimientos específicos a mujeres conversas y niños.

Empero, si bien es cierto que los gobiernos centroamericanos han otorgado la posibilidad de reconocimiento a las asociaciones religiosas, también lo es que aún existen restricciones que imposibilitan llevar a cabo los registros correspondientes por parte de los musulmanes -para el caso que me ocupa-, lo que redunda en la falta de información estadística, un desconocimiento básico de la práctica religiosa de este credo y, en el peor de los casos, la minimización de esta comunidad.

Con el fin de paliar esta situación es necesario enfrentar una serie de retos de índole político y jurídico, cuyo objetivo final redunde en romper con las prácticas gubernamentales, que más allá de otorgar un reconocimiento normativo de la libertad religiosa a través de la posibilidad de registro de las denominadas "asociaciones religiosas" por ejemplo, implemente estrategias para lograr dicho reconocimiento en la cotidianeidad. Si los

\footnotetext{
31 Algunas obras representativas son Clifton L. Holland, op. cit.; Roberto Marín Guzmán. "Los árabes en...", op. cit.; y Abdulmajeed Marin Nuñez, op. cit.
} 
gobiernos centroamericanos implementaran acciones para cumplir este propósito, sería posible lograr una integración social de los musulmanes, que más allá de complicar el panorama vinculado con cuestiones de -inseguridad regional provocada por el asentamiento de células extremistas -como ocurre en el caso de la Triple Frontera Latinoamericana-, complemente la riqueza religiosa y cultural de los países que conforman dicha región.

En este sentido, la presencia musulmana en Centroamérica debe mirarse a través de un cristal diáfano y no de uno opaco, toda vez que fuera de las etiquetas de extremismo que sólo son aplicables a una minoría, la colectividad se caracteriza por enriquecer el ámbito político, social, cultural e incluso económico de cualquier sociedad a la que se haya integrado.

Fuera de toda duda, la comunidad musulmana centroamericana continúa enfrentando grandes retos. No obstante, éstos no permearán en su visibilidad en el mediano y largo plazos, toda vez que el Islam, como un sistema de vida, va más allá de la necesidad de un reconocimiento legal. Un ejemplo de ello es que la carencia de un gran número de espacios físicos adecuados para llevar a cabo sus oraciones, no ha imposibilitado a la comunidad realizarlas día con día desde que ha sido posible tener cuenta de su presencia, a través de datos duros, en 1908.

Por último quiero señalar que el fenómeno que el Islam centroamericano representa es de suma relevancia para profundizar y comprender al Islam de nuestra América. En este sentido y con el fundamento de la información expuesta y analizada en este sucinto trabajo de investigación hago un llamado a explorar, problematizar y pensar el fenómeno del Islam enmarcado en esta región con el fin de minimizar los espacios vacíos en esta materia, ya que tanto en las particularidades como en las generalidades aún hace falta mucho por explorar.

Con el fin último de aportar al estado de conocimiento de la materia, será necesaria la construcción de variadas hipótesis desde diversas perspectivas -histórica, estadística e incluso geográfica-, que generen debates que enriquezcan la discusión alrededor de este tema, cuyo robustecimiento dependerá de las investigaciones que los especialistas e interesados -que cuenten con bases metodológicas para el desarrollo de investigaciones originales- pudiesen llevar a cabo.

Es comprensible la existencia de la posibilidad de que el interés en el tema no nazca de la curiosidad del lector. Este puede generarse si los argumentos vertidos hasta el momento se ponen en tela de juicio y se discuten con fundamentos, con bases sólidas que propicien la construcción y evolución del conocimiento en la materia objeto de estudio. 
Lo anterior, fuera de toda duda y más allá de los obstáculos a los que los interesados en el tema puedan enfrentarse, dará lugar a investigaciones novedosas, y por ende, relevantes y pertinentes. 


\section{Fuentes de información}

\section{Bibliohemerografía}

Álvarez de Toledo, Luisa Isabel, África versus América. La fuerza del paradigma, Córdoba, Junta Islámica, Centro de Documentación y Publicaciones, 2000.

Abdeluahed Akmir, compilador, Los árabes en América Latina. Historia de una emigración, Madrid, Siglo XXI, 2009.

Azcárate, Graciela, La inmigración árabe en América, "Inmigración árabe en América Latina", (2005), disponible en http://rootsweb.com/ domwgw/ arabesamerica.htm

Delval, Raymond, Les musulmans en Amérique Latine et aux Caraïbes, París, L'Harmattan, 1992.

Djinguiz, Mohammed, L'Islam dans l'Amérique centrale et dans l'Amérique du sud, "Revue du monde musulman", VI (1908), pp. 314-318.

Escalante, Pedro y Abraham Daura Molina, Sobre Moros y Cristianos, y otros Arabismos en El Salvador, San Salvador, Embajada de España en El Salvador y Agencia Española de Cooperación Internacional, 2001.

Holland, Clifton L., Enciclopedia de grupos religiosos en las Américas y la Península Ibérica: religión en Belice, "Programa Latinoamericano de Estudios Sociorreligiosos (PROLADES) Online", (2009), p. 19, disponible en http://www.prolades.com/cra/regions/cam/spanish/rel_guate09spn.pdf

Klich, Ignacio, compilador, Árabes y judíos en América Latina. Historia, representaciones y desafíos, Buenos Aires, Siglo XXI, 2006.

Marin Nuñez, Abdulmajeed, History of the Muslims in Belize, Indiana, Author House, 2010.

May, Sally. El Islam en Costa Rica, México, Centro y Sudamérica. Perfil de un nuevo movimiento religioso, Programa Latinoamericano de Estudios Sociorreligiosos (PROLADES) Online, (2011), p. 3, disponible http:// www.prolades.com/profiles/islam_spn.pdf

National Census Report, Belice, Caricom Capacity Development Programme, 2000.

Rein, Raanan, coordinadora, Árabes y judíos en Iberoamérica. Similitudes, diferencias y tensiones, Madrid, Tres Culturas, 2008.

Reis, João José, Rebelião escrava no Brasil. A história do levante dos malês em 1835, São Paulo, Companhia das Letras, 2003.

Rosemberg Fuentes, Velvet, El Islam centroamericano en números, "Archipiélago. Revista Cultural de Nuestra América", 87 (2015), pp. 5659. 
Rosemberg Fuentes, Velvet, El estudio del Islam en América Latina: trabajos académicos (1980-2010), "Mañongo, Revista Semestral de Historia y Ciencias Sociales", 44 (2015), pp. 13-41.

Rosemberg Fuentes, Velvet, La Triple Frontera latinoamericana y el Islam desde las acepciones del concepto de frontera, "Revista Convergencia Crítica”, 6 (2015), pp. 113-141.

Sills, M. David y Kevin Baggett, Islam in Latin America, "Southern Baptist Journal of Theology", 2 (2011), pp. 28-41.

Taboada, Hernán G. H., Nuestra América y el islam la mirada en el tercer milenio, "Archipiélago", 40 (2003), pp. 11-14.

Taboada, Hernán G. H., La sombra del Islam en la conquista de América, México, UNAM-Fondo de Cultura Económica, 2004.

Taboada, Hernán G. H., El moro en las Indias, "Latinoamérica. Revista de Estudios Latinoamericanos", 39 (2004), pp. 115-132.

Yusuf Hallar, Muhammad, Los musulmanes en América Latina y sus expectativas para el Nuevo siglo, "Islamérica Online", (1998), disponible en http://www.islamerica.org.ar/dosimpo.html

\section{Documentos}

Constitución de Belice, Parte II Protección de los derechos fundamentales y libertades, Belice, 1981, disponible en http://pdba.georgetown.edu/ Constitutions/Belize/belize81.html\#mozTocId483751

International Religious Freedom Report for 2012, Washington, Departamento de Estado de Estados Unidos, 2012, disponible en http://www.state.gov/j/ drl/rls/irf/religiousfreedom/\#wrapper

Ley de Asociaciones y Fundaciones sin fines de lucro, núm. 894, tomo 333, Diario Oficial, San Salvador, Ministerio del Interior, 17 de diciembre de 1996.

Ley sobre Asociaciones y Registro Central de Personas Jurídicas, Decreto núm. 1346, Managua, Junta de Gobierno de Reconstrucción Nacional de la República de Nicaragua, 15 de Noviembre de 1983.

Reglamento de la Ley de Asociaciones y Fundaciones sin fines de lucro, núm. 78, tomo 336, Diario Oficial, San Salvador, Ministerio del Interior, 21 de agosto de 1997. 


\section{Información recopilada en páginas electrónicas gubernamentales}

Belize Demographics and Population Data. Belize Population Census, Statistical Institute of Belize, Belmopan, 2010, disponible en http://www. belize.com/belize-demographics

Bureau of Democracy, Washington, Human Rights and Labor, U. S. Department of State, 2012, disponible en http://www.state.gov/j/drl/rls/ irf/religiousfreedom/index.htm?dlid\#wrapper

Dirección Adjunta de Culto, San José, Gobierno de la República de Costa Rica, 2014, disponible en $h t t p: / / w w w . r r e e . g o . c r / i n d e x . p h p ? s e c=$ ministerio\&cat $=$ protocolo\& cont $=447$

Misión, visión y objetivos institucionales, Ministerio de Relaciones Exteriores y Culto, San José, Gobierno de la República de Costa Rica, 2014, disponible en $h t t p: / / w w w . r r e e . g o . c r / ? \mathrm{sec}=$ ministerio\& $\mathrm{cat}=$ acerca\&cont $=401$

Muslim population by country, "The Future of the Global Muslim Population", Pew Research Center, Religion \& Public Life Project, disponible en http:// features.pewforum.org/muslim-population/

$\mathrm{s} / \mathrm{n}$, Belize Religion. Belize Visitor Online, Belice, 2007, disponible en http:// www.belizevisitor.com/religion-in-Belize.html 
